\title{
أثر الحكم الجزائي على الوضع الوظيفي للموظف
}

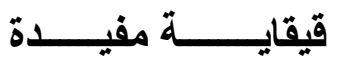

كلية الحقوق

جامعة الإخوة منتوري

قسنطينة

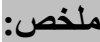

إن القاعدة العامة هي استقلال العقوبة الجزائية عن

العقوبة التأديبية ، فلكل منهما مجال تطبيق خاص به و

غرض تسعسـى إلى تحقيقه ، و الاستثنــــاء هو وجود

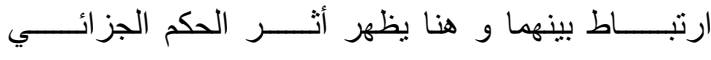

على الوضع الوظيفي للموظف، و بما أن هذا الأثر يتجاذبه

قانونين هما القانون الجزائي و القانون المنظم للوظيفة

العمومية ، حاول المشـــرع من خلالهما توضيح الأثر

المتبـــــادل بين الجزائــي و التأديــــبـ فيما بيتعلق

بوضعية الموظف الوظيفية ، و هو ما حاولنا التطرق له من

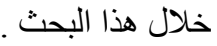

\section{Abstract:}

يســأل الموظـف عـن تصـرفاته مسن عـدة The general rule is the independence of criminal punishment of disciplinary punishment, each has its own application domain and the purpose, sought and the exception is a link between them, and here appears the penal implication of the employment status and since these two laws talk him impact criminal law and the law governing the public service, through wich the legislator tried to clarify mutual impact between disciplinary and penal code in the status of employee and what we've tried to address trough this search 


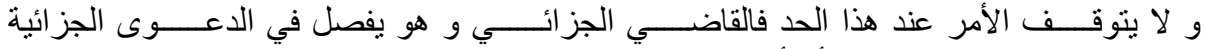

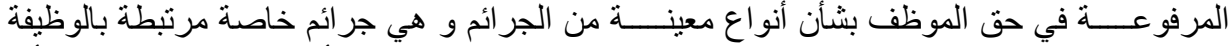

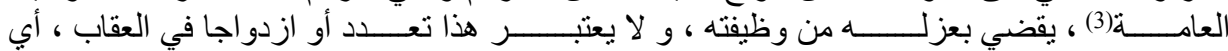

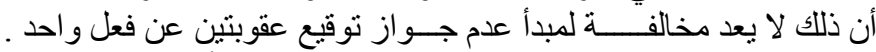

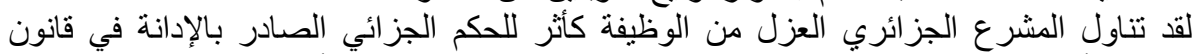

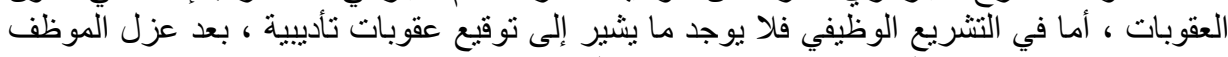

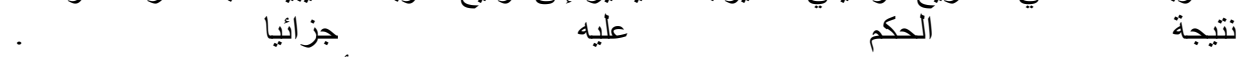

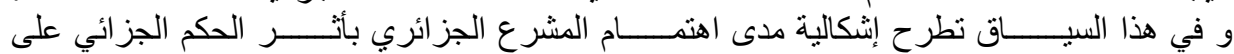

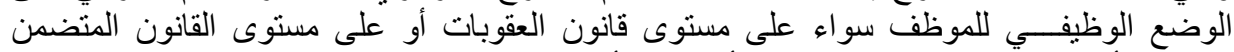
القانون الأساسي العام للوظيفة العومية ، أو بعبارة أخرى إذا كان المتهم في موضون التوع الدعوى العمومية

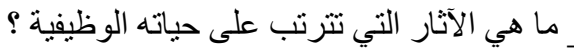
موظفاف : مان الإنيان

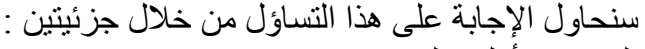

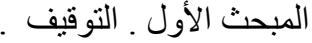

المبحث الثاني ـ العزل من الوظيفة

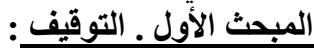

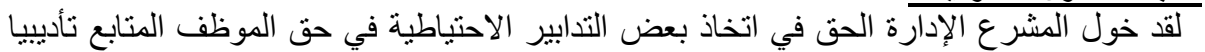

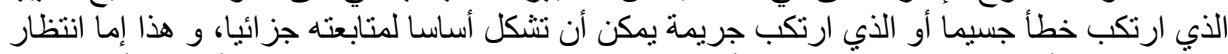

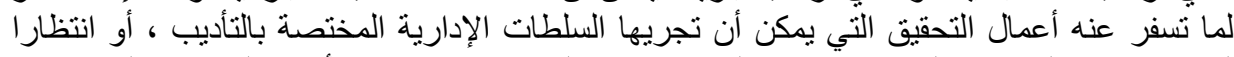

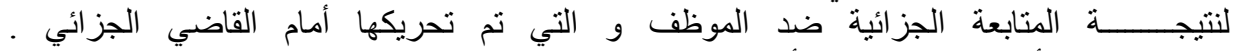

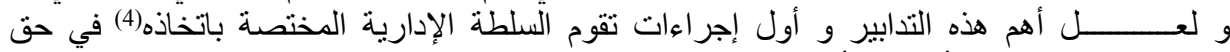

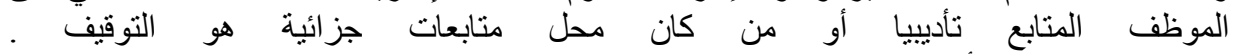

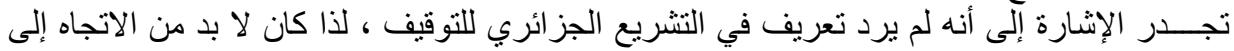

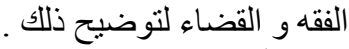

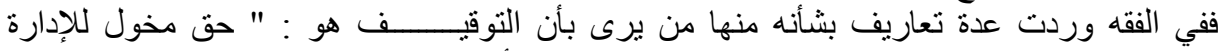

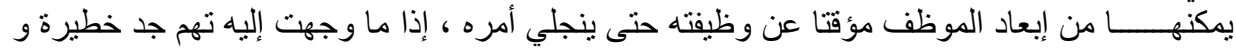

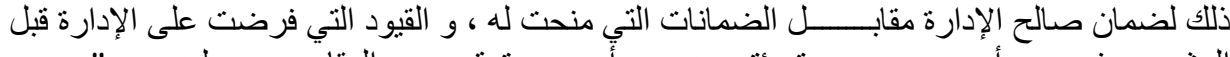

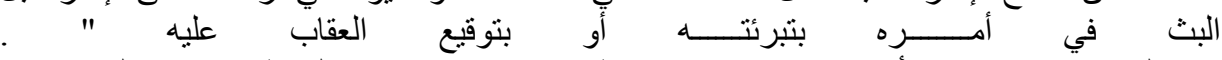

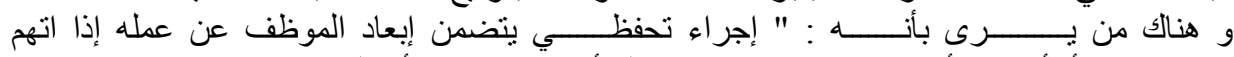

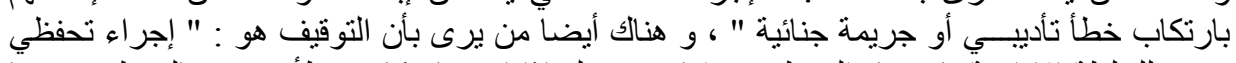

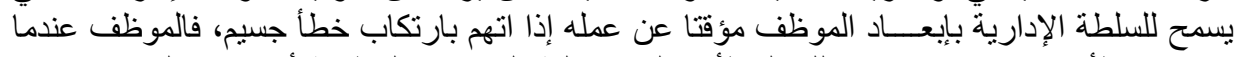

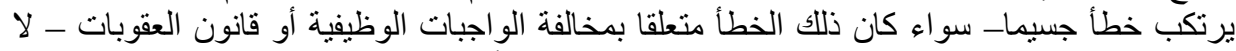

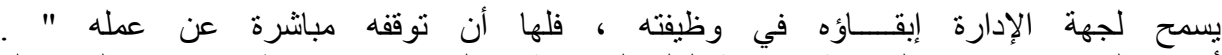
أما في القضاء فجاء عن المحكمة الإدارية العليا المصرية : "التوقيف هو إسقاط مؤقتا لا يتولى خلادله

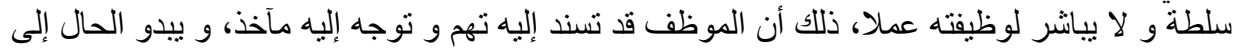

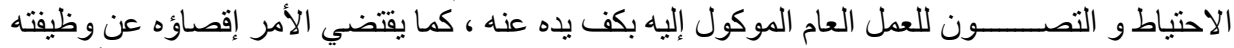
ليجري التحقيق في جو خال من مؤثراته ، و بعيدا عن سلطاته توصلا إلى النبلاج النياج الحقيقة في أمر هذا

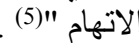

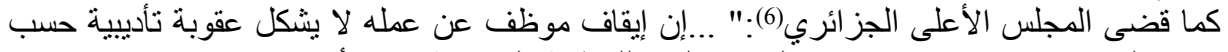

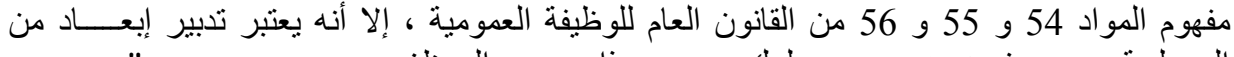

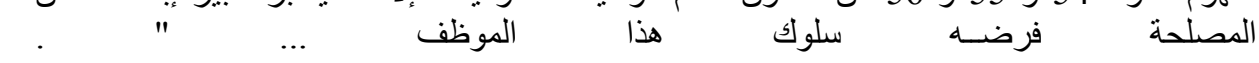


إن توقيف الموظف يكون في حالتين حددتهما المادتين 173 و 174 على التو الي من الأمر رقم 06 / 03

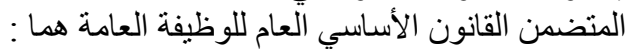

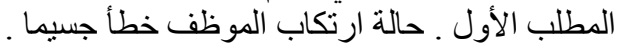

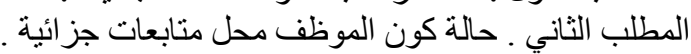

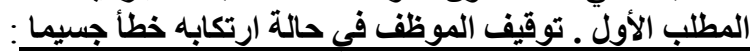

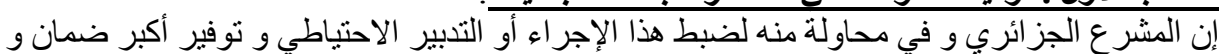

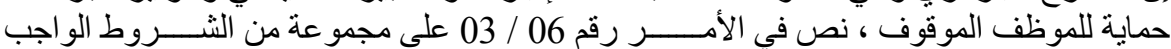

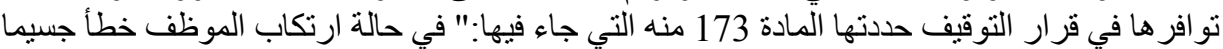

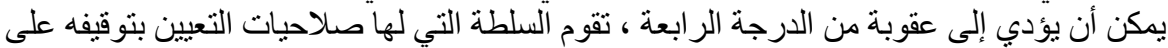

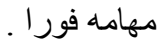

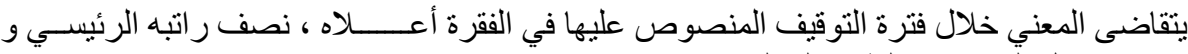

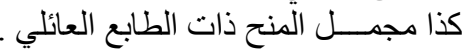

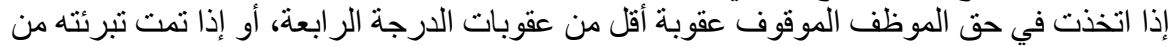

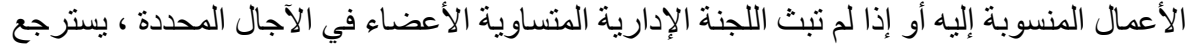

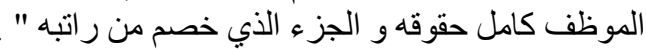

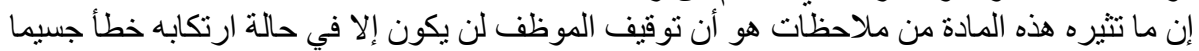

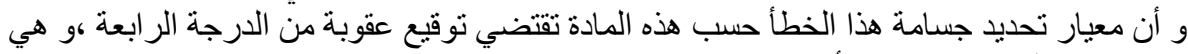

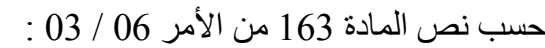

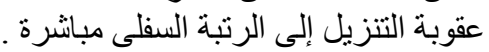
عقوبة التسريح .

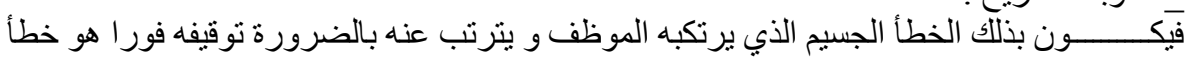

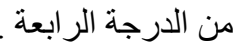

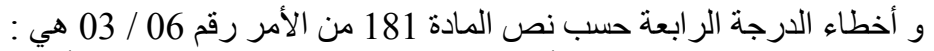

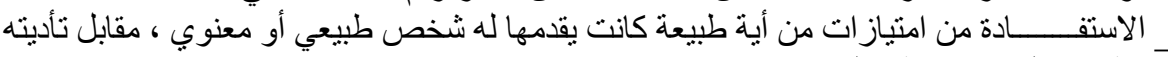

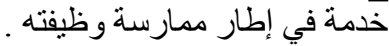
ارتكاب أعمال عنف على أب شخص في في مكان العمل .

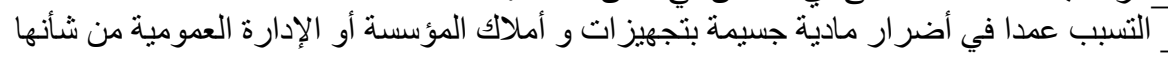

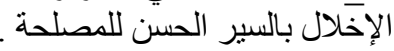

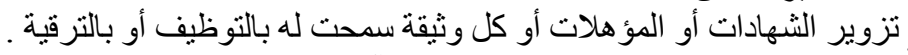

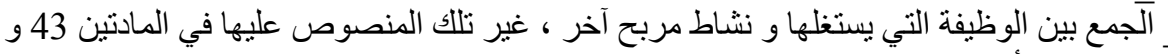
4

هذا و يصدر قر ار توقيف الموظف عن مهامه عن السلطة التي لهاصلاحيات التعيين، كما أن السلطة

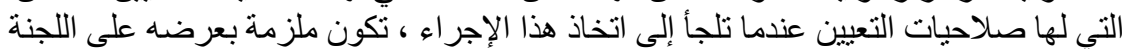

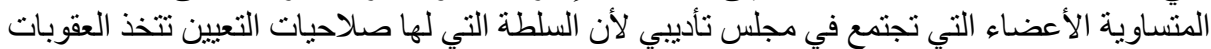

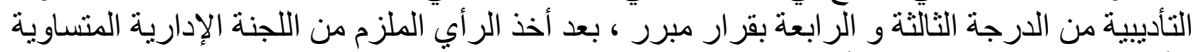
الأعضاء المجتمعة كمجلس تأديبي . الأنس

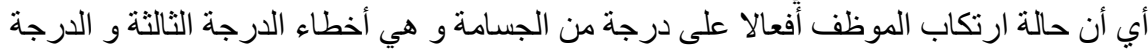

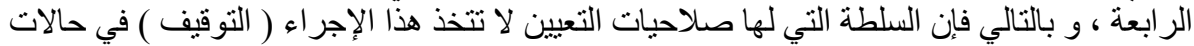

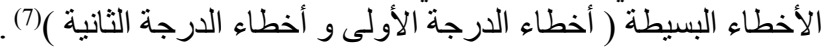

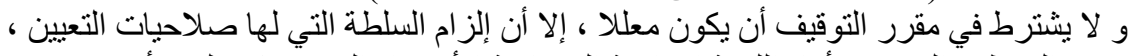

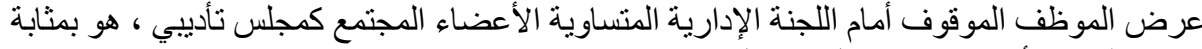
ضمانة له ضد أي تعسف محتمل من قبل الإدارة . 
فالتوقيف إذن هو إجر اء مهم و مؤقت الهذف منه إبعاد الموظف عن مهامه لمدة محددة ، في انتظار

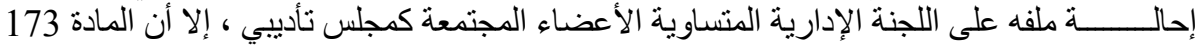

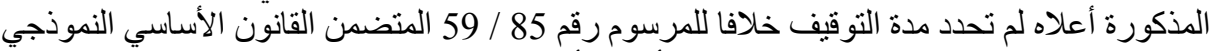

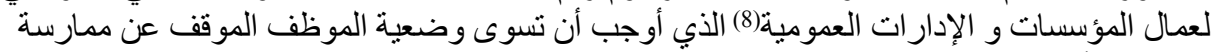

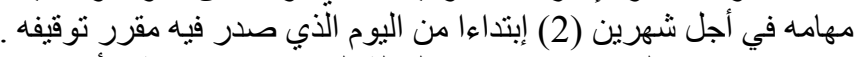

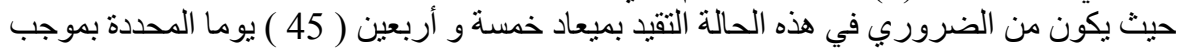

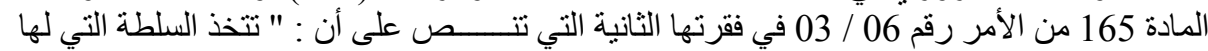

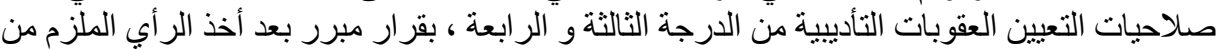

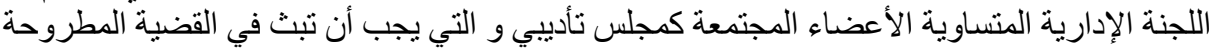

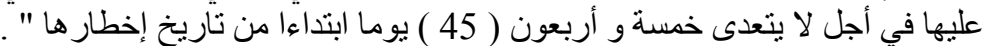

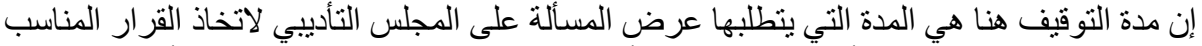

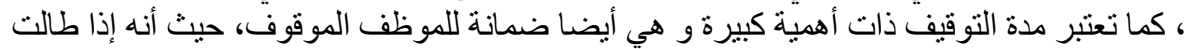

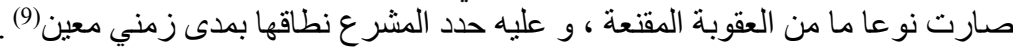

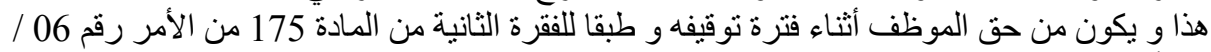

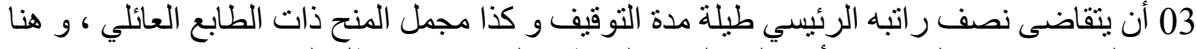

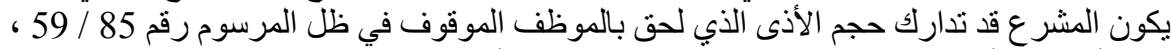

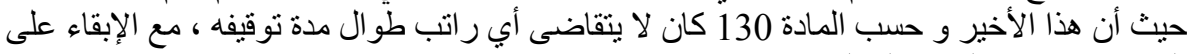

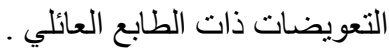

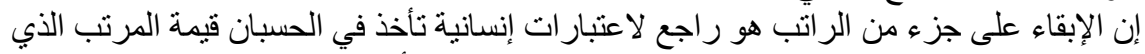

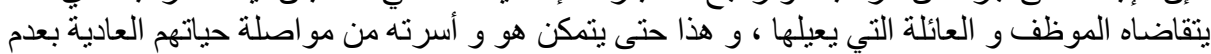

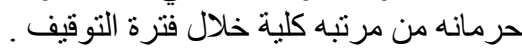

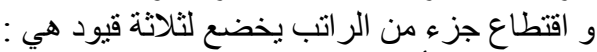

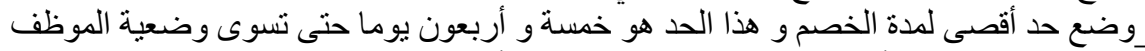

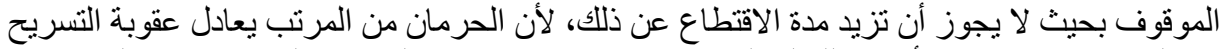

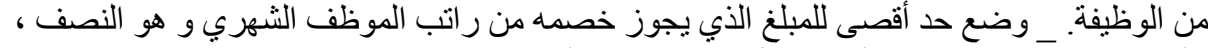

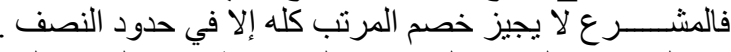

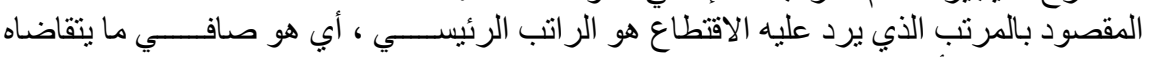

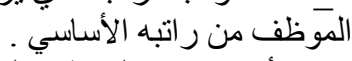
كما أنه من حق المّ الأفف الموقوف و حسب المادة 173 دائما استرجاع كامل حقوقه و الجزء الذي

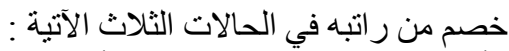

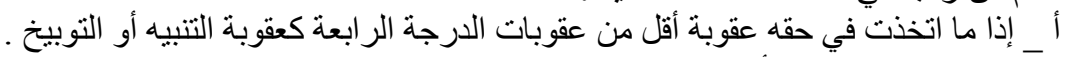

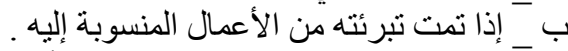

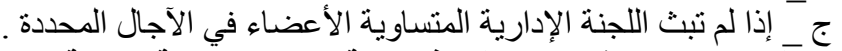

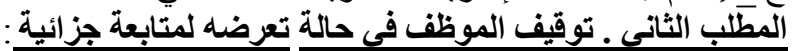

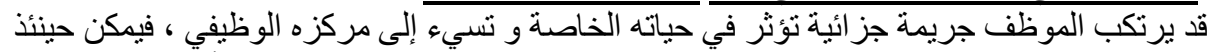

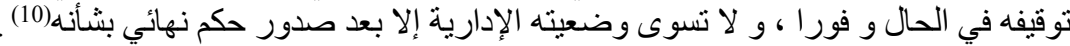

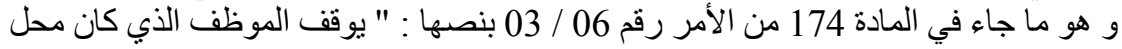

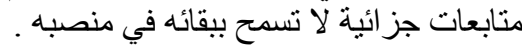

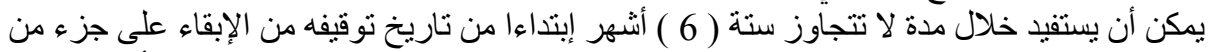

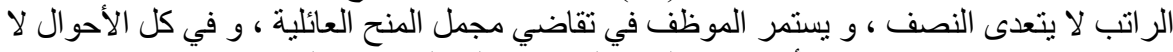

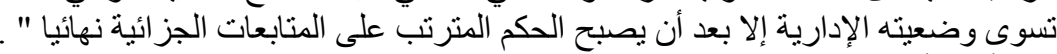
إن الأثر الأساسي للتوقيف هو الإبعاد العاجل للموظف الذي كان الذئ محل متابعات جز ائية لا تسمح بيقائه 
في منصبه من قبل السلطة التي لها صلاحية التعيين،كما يتولى مسؤولوه المباشرون استرجاع جميع

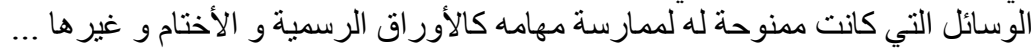

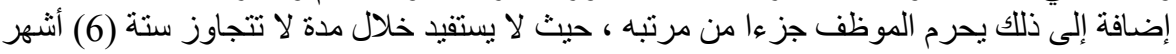

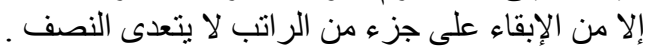

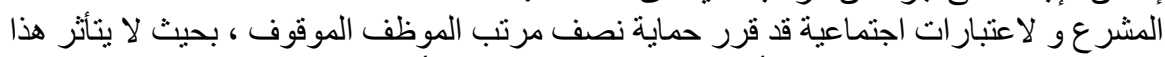

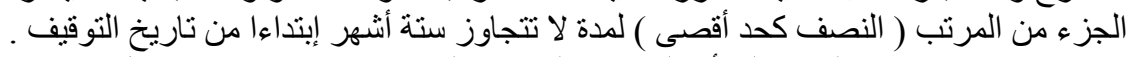

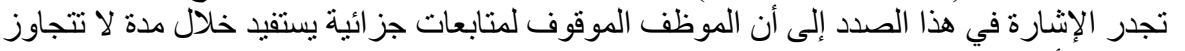

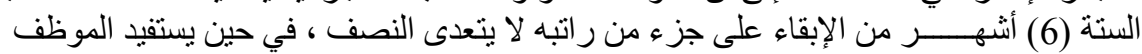

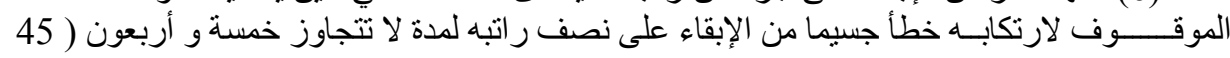

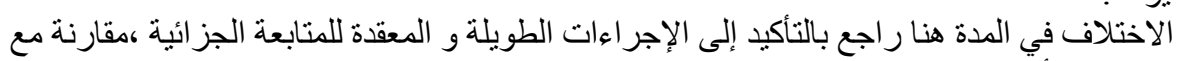

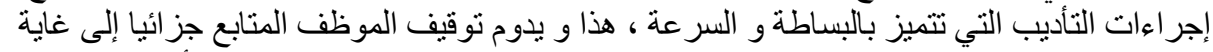

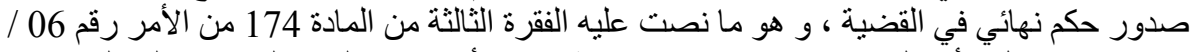

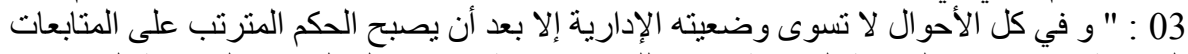

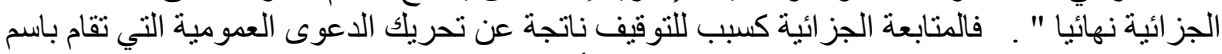

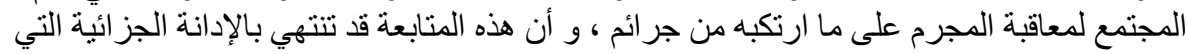

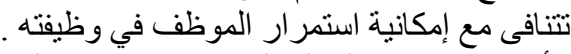

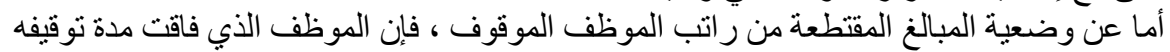

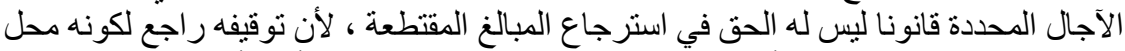

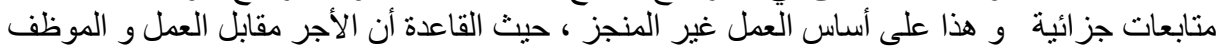

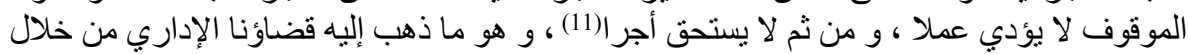

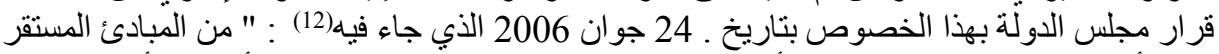

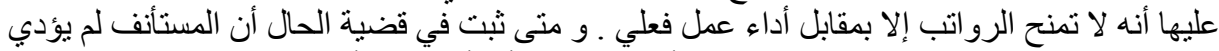

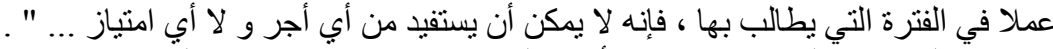

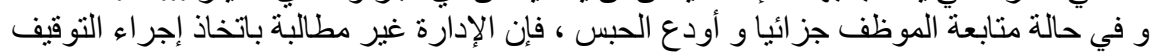

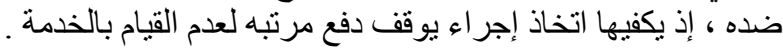

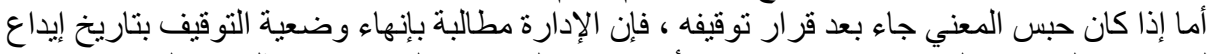

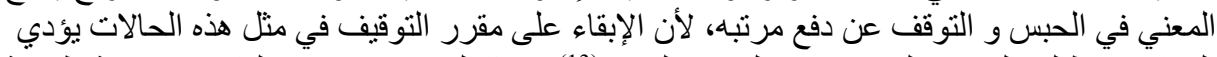

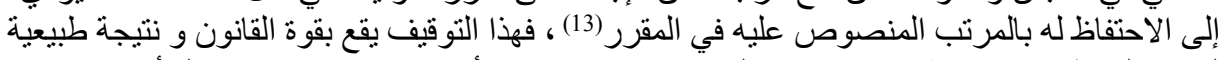

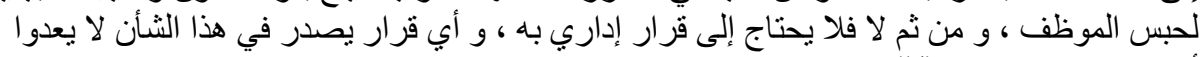

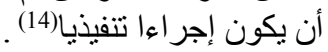

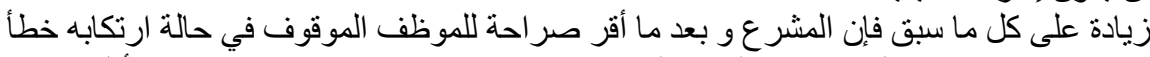

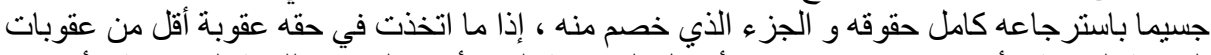

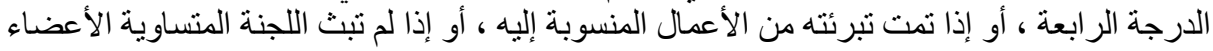

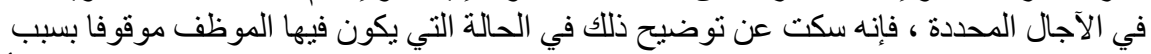

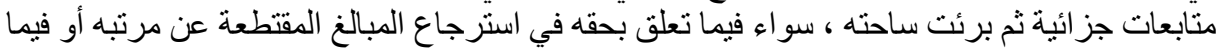

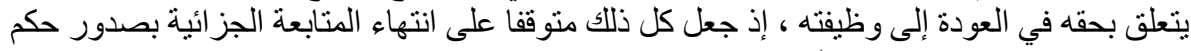

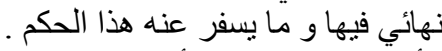

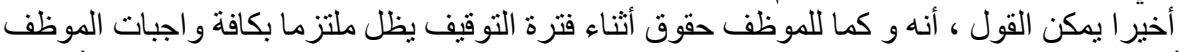

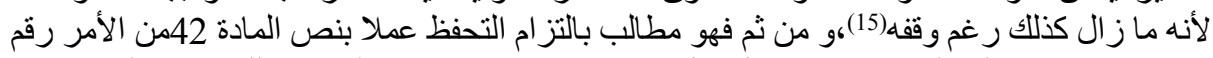

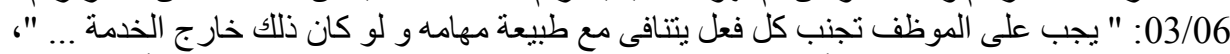

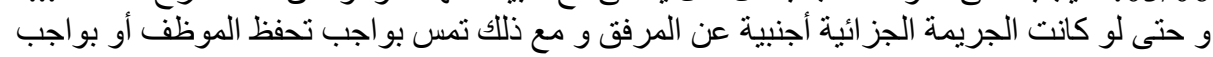




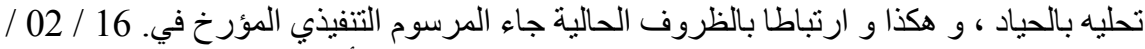

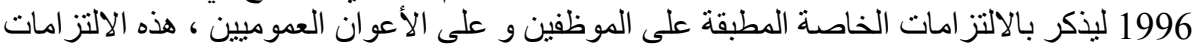

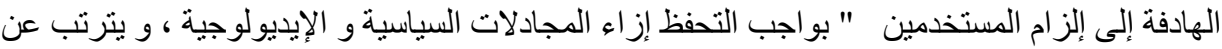
و اجب التحفظ حتى خارج المصلحة الامتناع عن كل عمل و سلوك و تعليق يعتبر متعارضا ولئه و وظائفهر

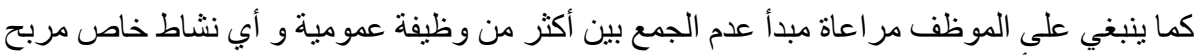

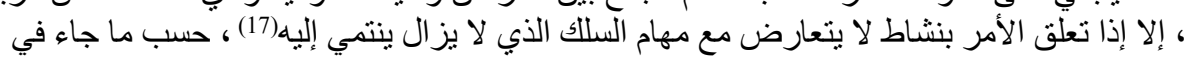

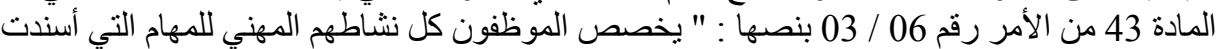

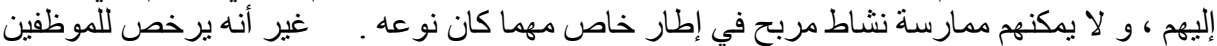

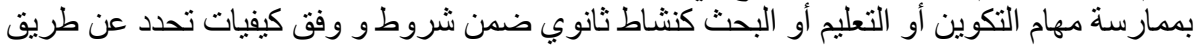

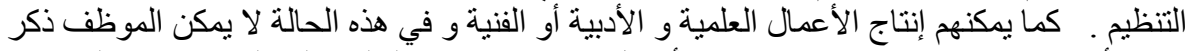

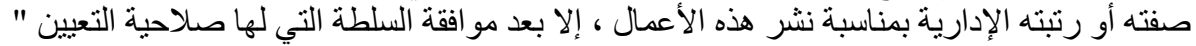

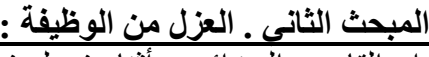

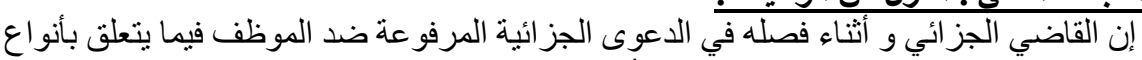

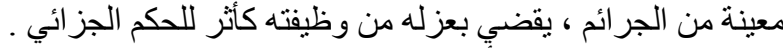

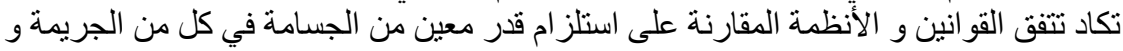

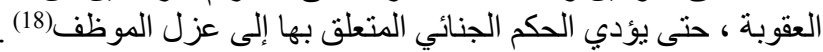

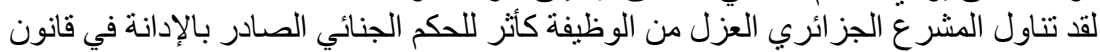

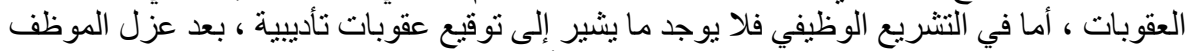

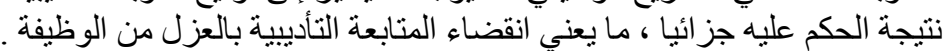

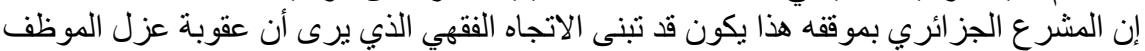

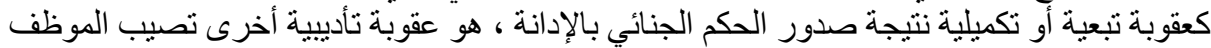

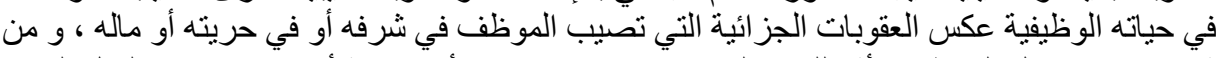

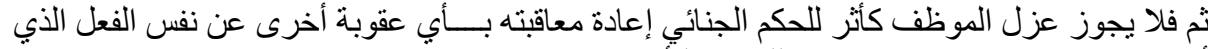

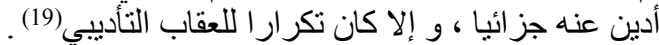

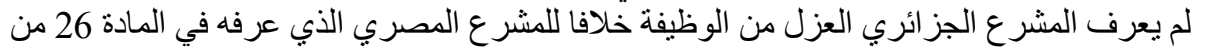

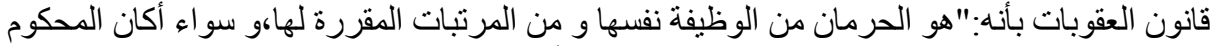

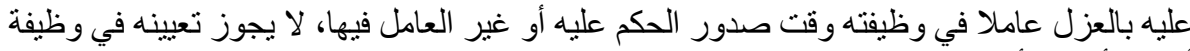
أميرية أو نيله أب مرتب طيلة فيلة مدة يقدر ها الحكم " .

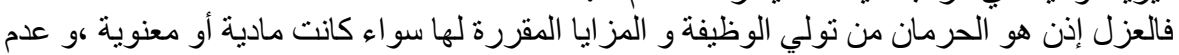

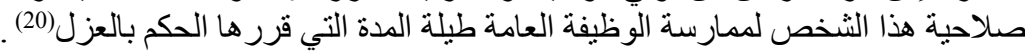

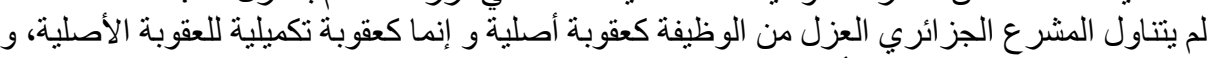

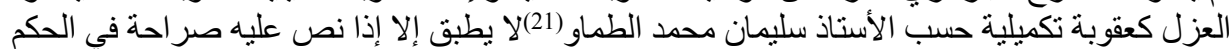

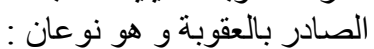
عقوبة تكميلية وجوبية : كما هو الحال في جر ائم الرشوة و اختلاس الأمو ال العامة و التزوير ...

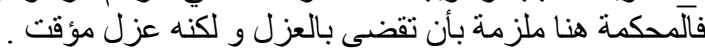

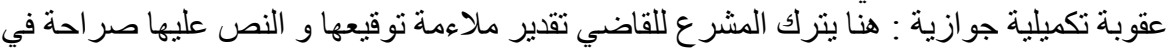

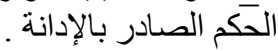
و بالتالي سو اء كانت العقوبة التكميلية وجوبية أو جوازية ، فإنها لا لانحق المحكوم عليه إلا إذا نص عليها

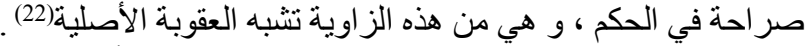
في هذا الصدد نصت المادة 4 من قانون العقوبات(23) على أن : " العقوبات التكميلية هي التي لا يجوز 
الحكم بها مستقلة عن عقوبة أصلية ، فيما عدا الحالات التي ينص عليها القانون صر احة و هي إما

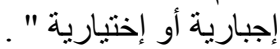
أما العقوبات التكميلية حسب المادة 9 من نفس القانون هي :

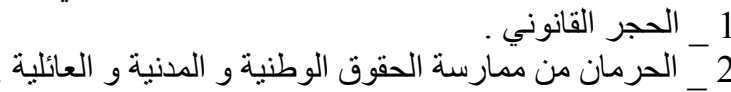
3 4 5 - المصادرة الجز ائية للأمو ال . 6- المنع المؤقت من ممارسة مهنة أو نشاط . إبلاق المؤسسة .

8 9

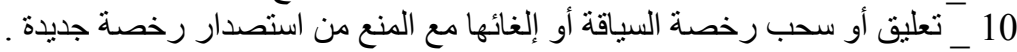
11 12

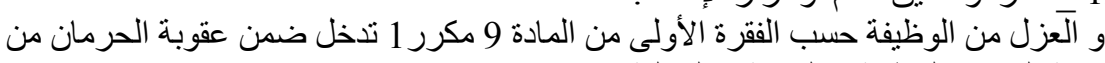

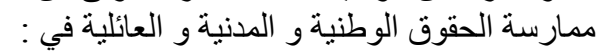

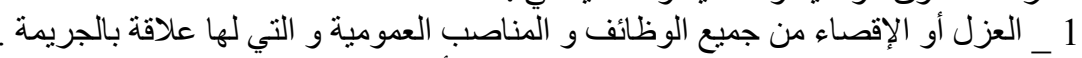

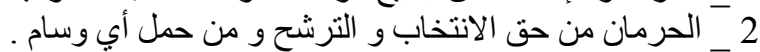
3

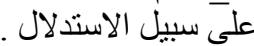
4 ـ الحرمان من الحق في حمل الأسلحة، و في التدريس ، و في إدارة مدرسة أو الخدمة في مؤسسة

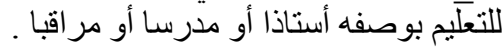
5

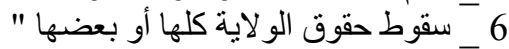

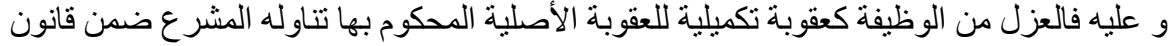
!

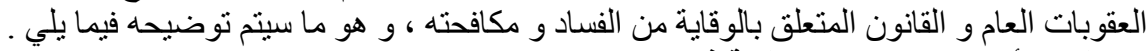

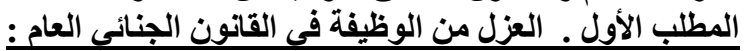

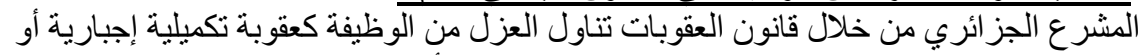

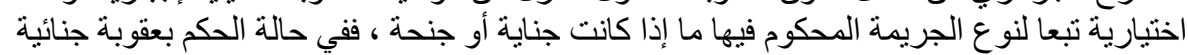

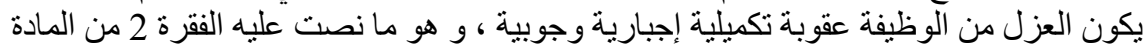

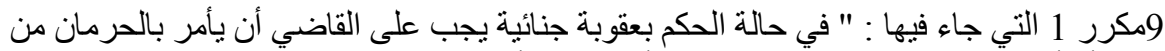

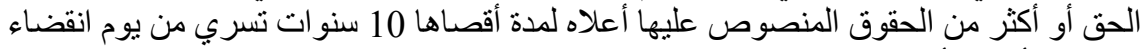

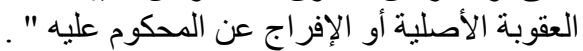
فالعزل كعقوبة تكميلية للعقوبة الأصلية الجنائية حسب نص الإدية المادة بعد وجوبياو ليس جوازيا للقاضي

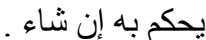

فإذا حكم القاضي بعقوبة جنائية يجب أن يشمل حكمه العزل أيضاو إلا كان حكمه مشوبا بالقصور و

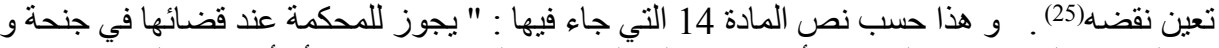

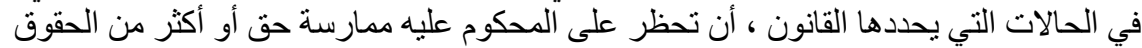

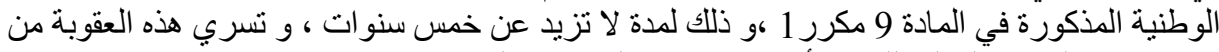

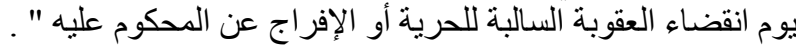

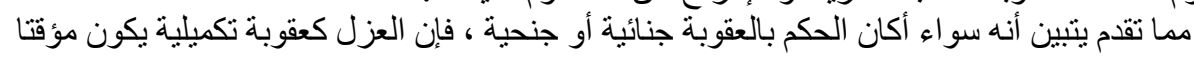




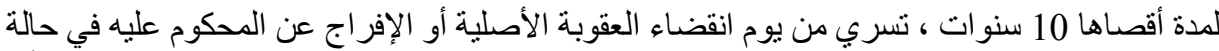

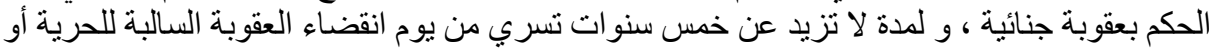

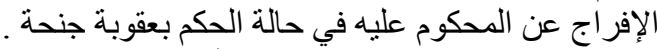

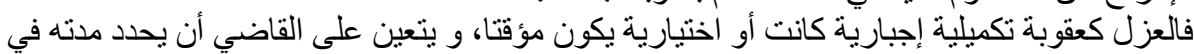

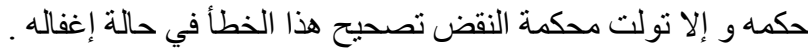

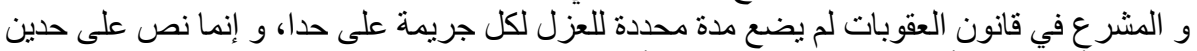

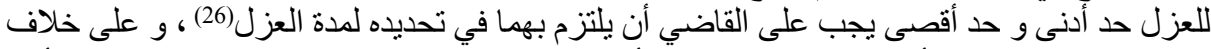

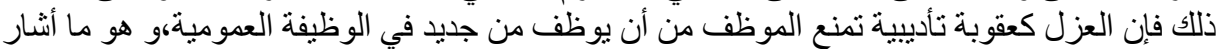

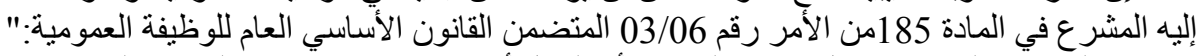

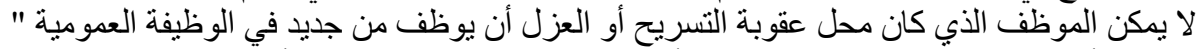

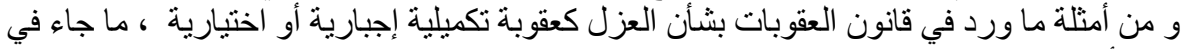

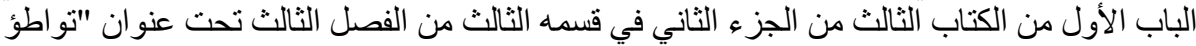

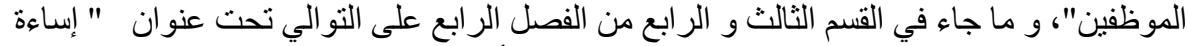

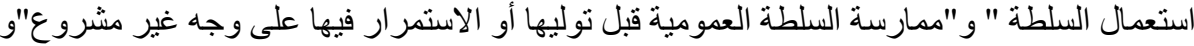
ما جاء في القسم الخامس من الفصل السابع تحت عنوان " التزوير في بعض الون الونائق الإدارية و

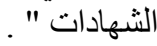
المادة 112 :"إذا اتخذت إجر اءات مخالفة للقو انين و كان تدبير ها عن طريق اجتماع أفر اد أو هيئات

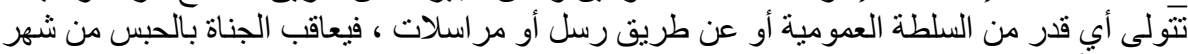

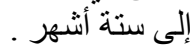
و يجوز علاوة على ذلك أن يقضي بحرمانهم من حق أو أكثر من الحقوق المبينة في المادة 14 و من

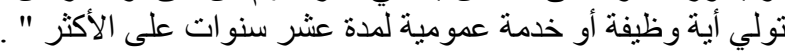

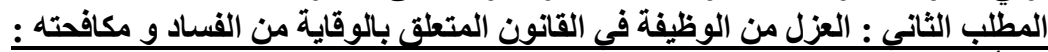

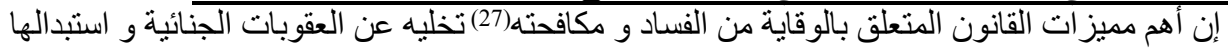

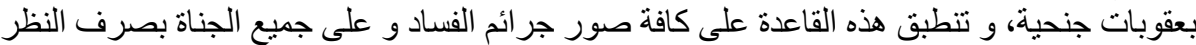

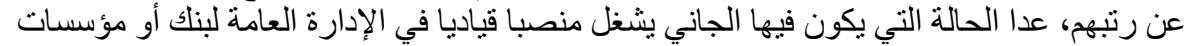

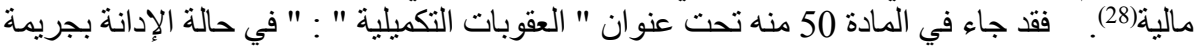

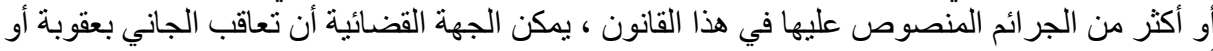

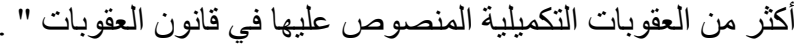

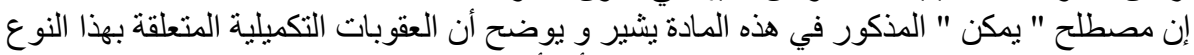

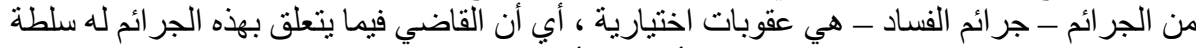

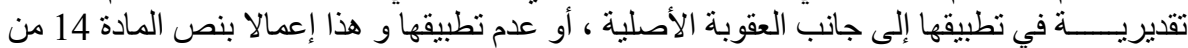

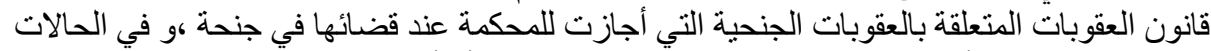

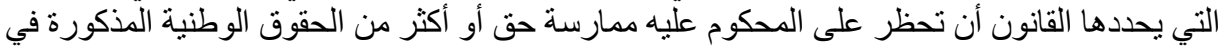

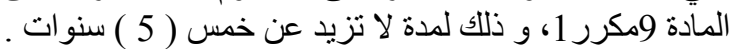

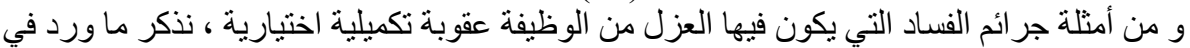

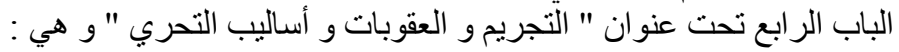

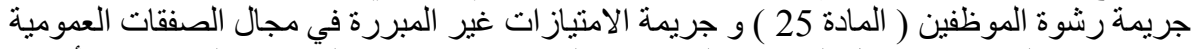

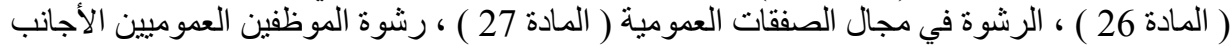

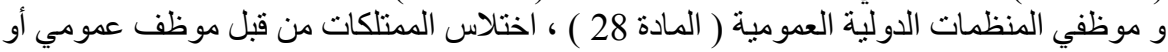

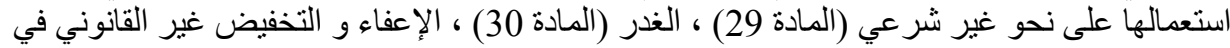

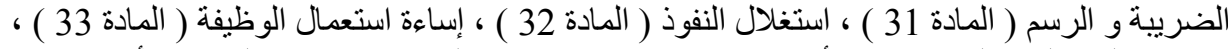

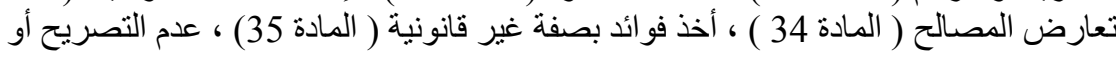


التصريح الكاذب بالممتلكات ( المادة 36 ) ، الإثر اء غير المشروع ( المادة 37 ) ) ، تلقي الهديا ( المادة

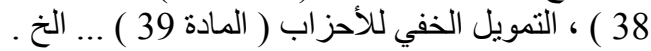

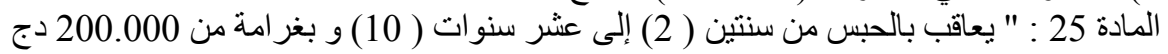
إلى 1.000 .000 دم:

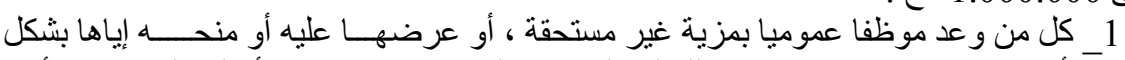

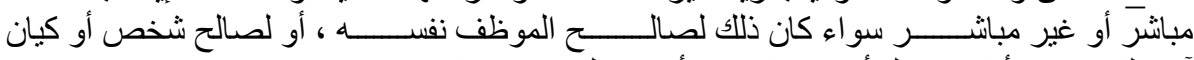

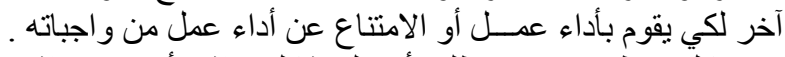

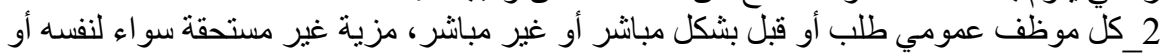

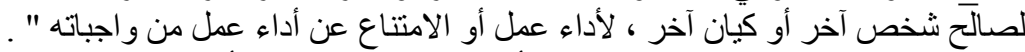

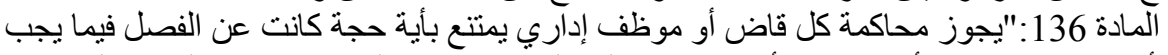

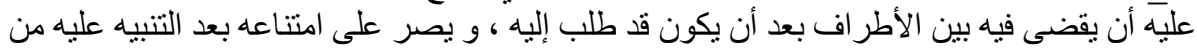

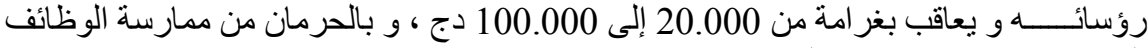

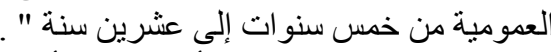

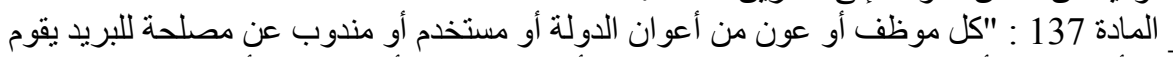

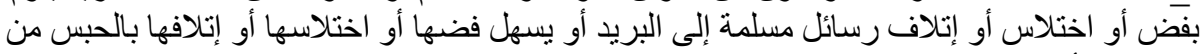

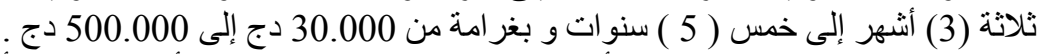

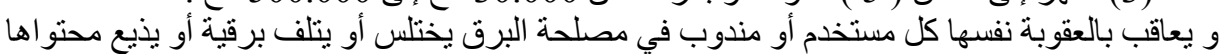

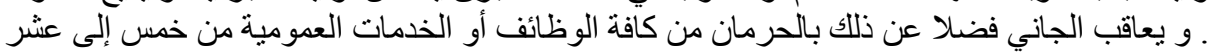

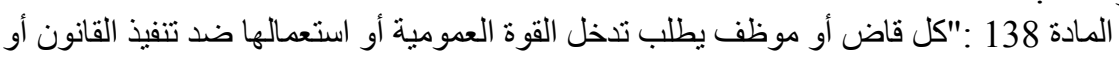
سنوات "

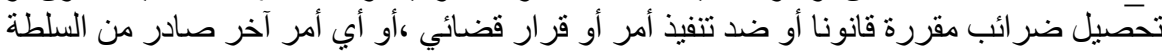

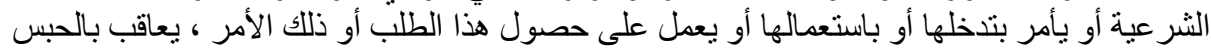

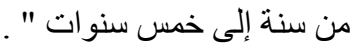

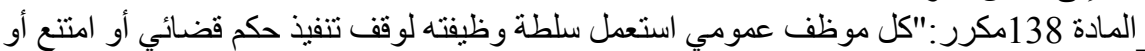

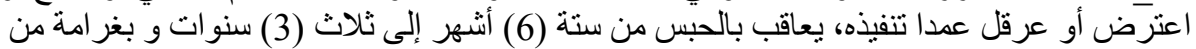
20.000 دج إلى 130000000 المادة 139 : " و يعاقب الجاني فضلا عن ذلاد الك بالحرمان من حق أو أكثر من الحقوق الواردة في الكي

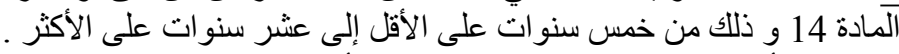

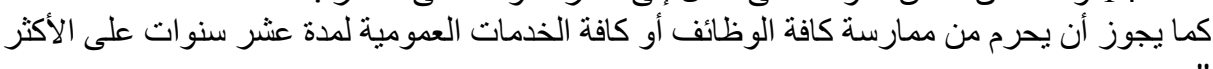
"المادة 142 : " كل قاض أو موظف أو ضابط عمومي فصل أو عزل أو أوقف أو حرم قانونا من

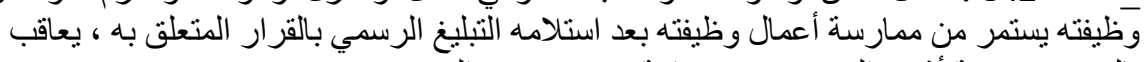

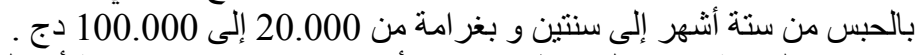

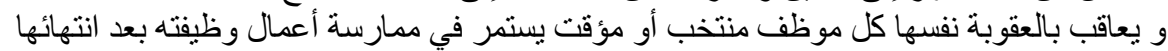

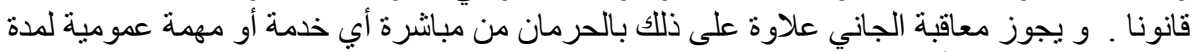

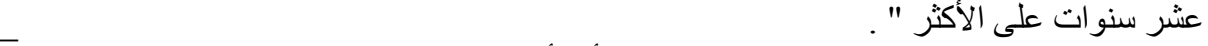

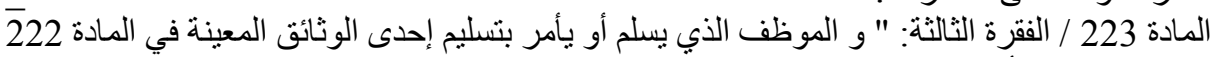

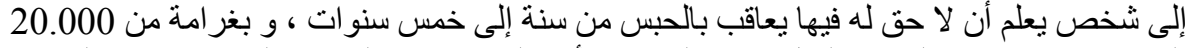

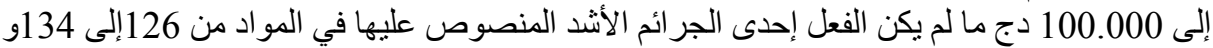

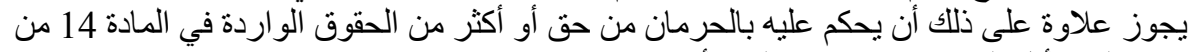

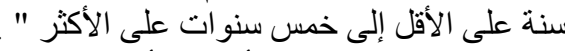

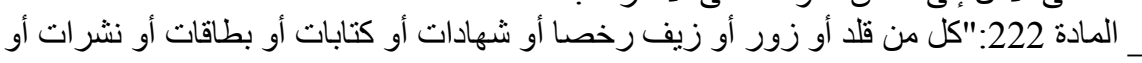




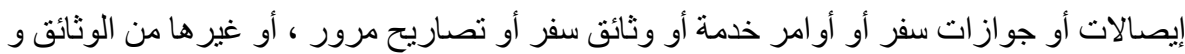

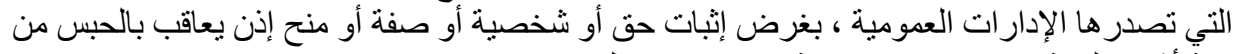

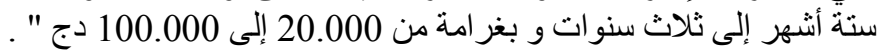

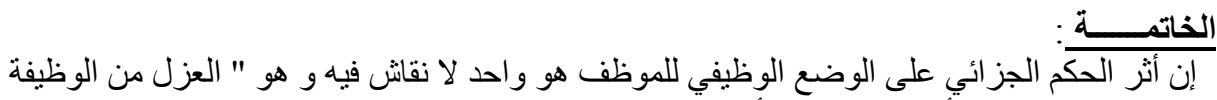

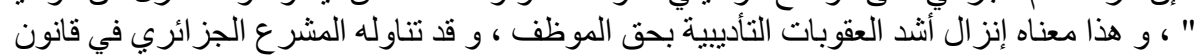

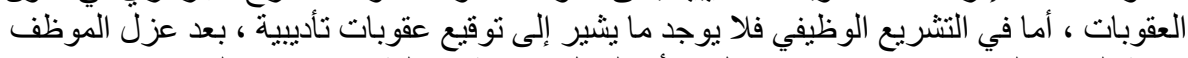

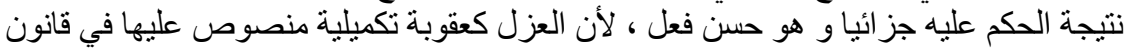

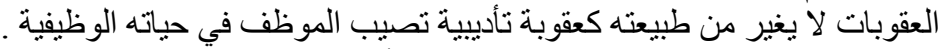

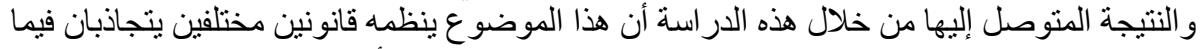

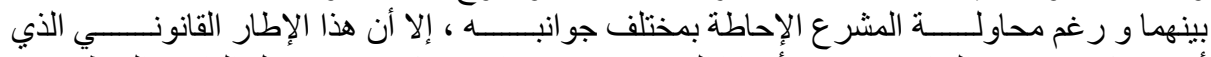

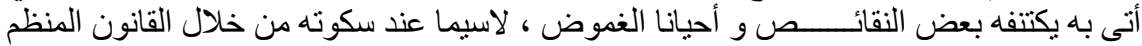

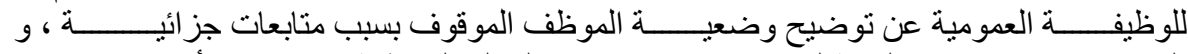

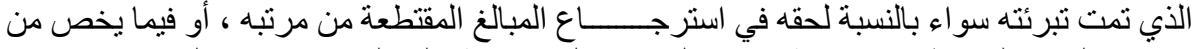

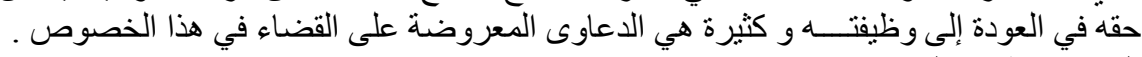

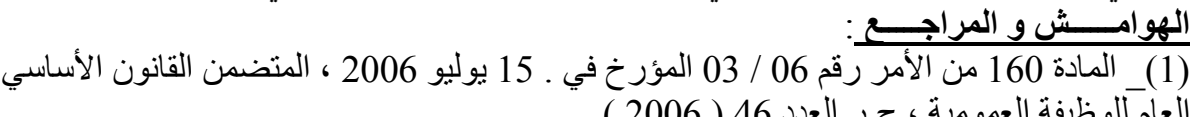
العام للوظيفة العمومية ، ج ر العرد العدد 46 ( 2006 ( 200 ) .

(2)- George Dellis , Droit pénal et droit administratif ( L'influence des principes du droit pénal sur le droit administratif répressif ), LGDJ , Paris , 1997, p . 239.

(3)_ محمد عصفور ، جريمة الموظف العام و أثرها في وضعه التأديبي ، دار النهضة العربية ،

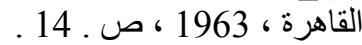

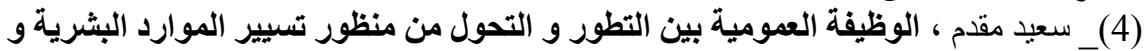

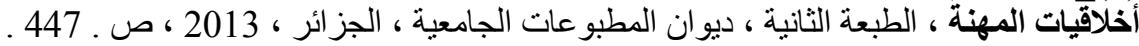

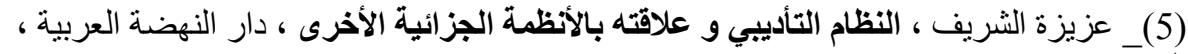

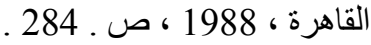

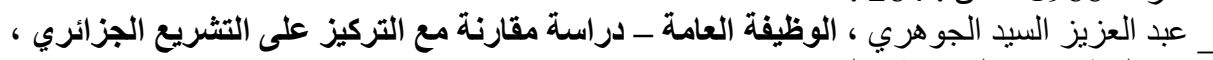

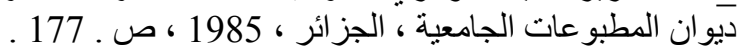

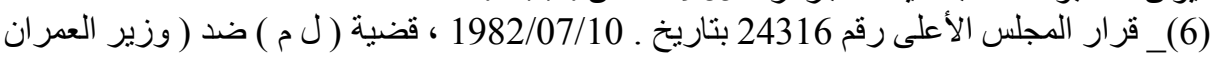

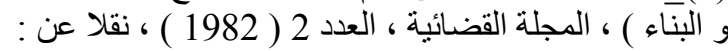

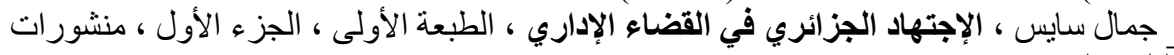

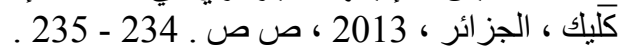

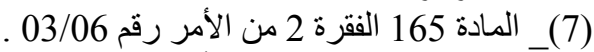

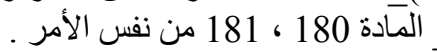

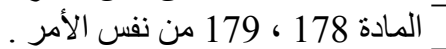

(8)_المادة 130 من المرسوم رقم 59/85 المؤرخ في 23 مارس 1985 المتضنمن القانون الأساسي

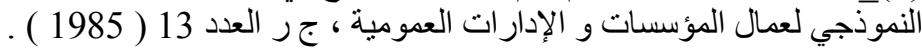
(9)_ سليمان محمد الطماوي ، ضمانات الموظفين بين النظرية و التطبيث ، مجلة العلوم الإدارية ،

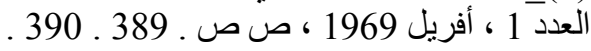
إن وصف مقنعة حسب GeorgeDellis: 


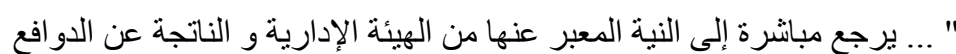

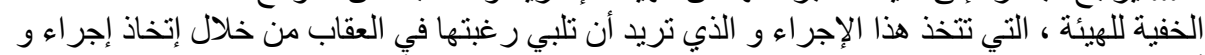

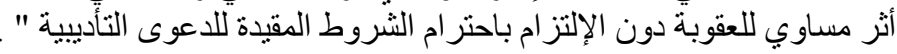

-George Dellis, op . cit, p. 150 .

(10)_ عبد الوهاب رافع ، نزاعات الوضعية الفردية للموظفين و العاملين بالإدارة العمومية من خلال

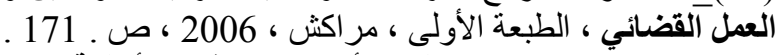

(11)_ عزيزة الثريف ، النظام التأديبي و علاقته بالأنظمة الجزائية الأخرى ، المرجع السابق ، ص .

(12)_قرار مجلس الدولة رقم 3998 بتاريخ . 24 / 06 / 2002 ، قضية ( ب ج ) ضد ( مدير مركز

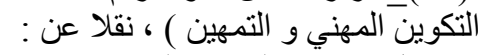

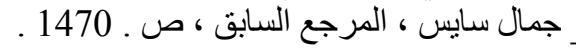

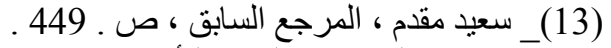

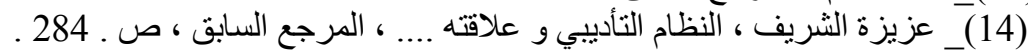

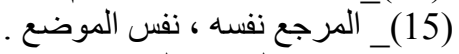

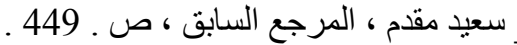

(16)_فريدة أبركان ، تعليق على قرار رقم 001192 ، مجلة مجلس الدولة ، العدد 1 ( 2002 ) ، ص (17)_ سعيد مقدم ، المرجع السابق ، ص . 449 .

(18) _ خالد خليل الطاهر ، أثر الحكم الجنائي على الموظف العام في النظام السعودي ، الطبعة ،

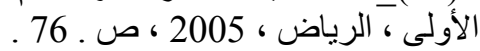

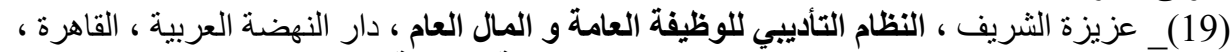

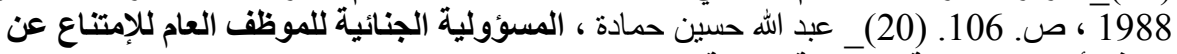

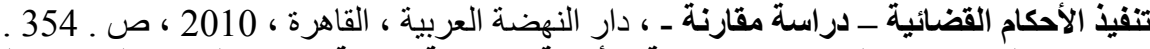

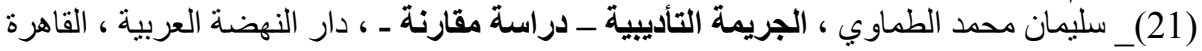

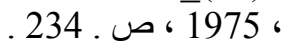

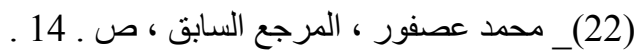

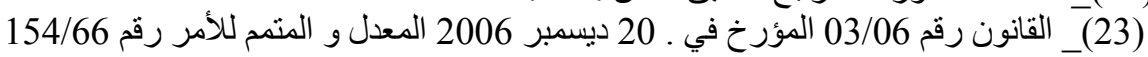

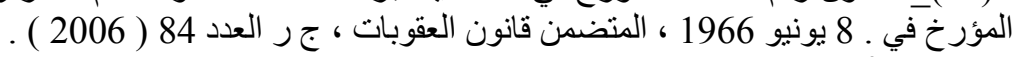
(24)- Fric Desmons , La responsabilité pénale des agents publics , 1 ère Edition, Presse universitaire de France, Paris, 1998, pp . 114 . 115. - Serge Petit, La responsabilité pénale des agents (Des trois fonctions publiques ), $3^{\text {ème }}$ Edition, Berger-Levrault, Paris , 2001, pp . 211 . 212. عبد الله حسين حميدة ، المرجع السابق ، ص ص . 368 . 368 . 368 . 360

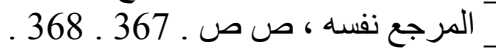

(27)_ القانون رقم 01/06 المؤرخ في 20 فبر اير 2006 ، 206 ، المتعلق بالوقاية من الفساد و مكافحته و

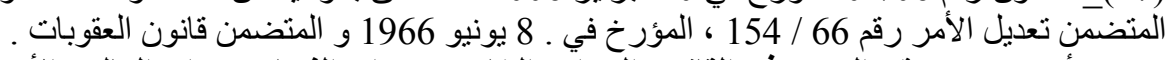

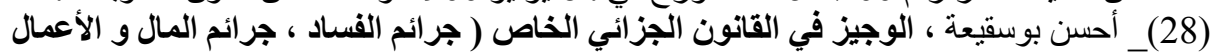

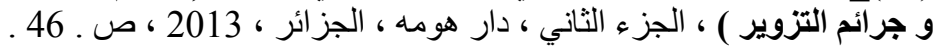

